\title{
Silica coating application on heat-cured acrylic resin plates towards the surface hardness and the amount of residual monomers
}

\author{
Rosa Sharon Suhono ${ }^{1 *}$, Endang Wahyuningtyas ${ }^{1}$, Titik Ismiyati ${ }^{1}$ \\ 1Department of Prosthodontics, Faculty of Dentistry Gadjah Mada University, Indonesia
}

\begin{abstract}
Introduction: Silica has been used as a coating material on acrylic resin denture plates to reduce the attachment of $C$. albicans, and acrylic resin denture coating application has been shown to increase the resistance. Acrylic resin as denture plate has many advantages, including good aesthetical aspect, easy to be manipulated, and relatively low costs. Acrylic resin also has disadvantages, namely the presence of residual monomers, low abrasion resistance, and broken easily. Residual monomers have poor biocompatibility and can weaken the mechanical strength of acrylic resin dentures. The purpose of this study was to analyse the silica coating application on heat-cured acrylic resin plates towards the surface hardness and the amount of residual monomers. Methods: This study used as much as 40 rod-shaped heat-cured acrylic resin specimens measured $13 \times 13 \times 2 \mathrm{~mm}$. Specimens were divided into 2 groups ( $=20$ ), namely the control group and the acrylic resin plate group applied with silica coating. Specimens in the treatment group applied with silica coating material using the dip-coating method. The surface hardness was tested using the Vickers hardness tester, and the amount of residual monomers was tested using gas chromatography. All data were analysed using an independent t-test. Results: Surface hardness in the group applied with silica coating was significantly higher than the control group $(p<0.05)$, while the remaining monomers of acrylic resin plate specimens in the group applied with silica coating were significantly lower than the control group $(p<0.05)$. Conclusion: Silica coating increases the surface hardness and decreases the amount of residual monomer of heat-cured acrylic resin.
\end{abstract}

Keywords: Silica coating, surface hardness, residual monomer, acrylic resin

p-ISSN: 1979-0201, e-ISSN: 2549-6212; Available from: http://jurnal.unpad.ac.id/pjd/article/view/19310

DOI: 10.24198/pjd.vol31no2.19310

Submission: Feb 2, 2018; Reviewed: Mar 19, 2019; Accepted: Jun 27, 2019; Published online: Jul 31, 2019

\section{INTRODUCTION}

The loss of one or more teeth highly affects the patient's appearance and has become the main reason for patients to perform denture treatment. Dentures are divided into two types, namely removable dentures and fixed dentures. Denture is a popular treatment for a variety of considerations, especially if the patient is contraindicated for treatment with a dental

"Corresponding author: Rosa Sharon Suhono, Department of Prosthodontics, Faculty of Dentistry Gadjah Mada University, Indonesia. Denta 1, Sekip Utara, Yogyakarta, Special Region of Yogyakarta, Indonesia, 55281. Phone: +62 822-4576-0112; Email: rosa.sharons11@gmail.com 
implant and does not want teeth extraction for fixed denture appliances.

Polymethyl-methacrylate (PMMA) acrylic resin is a material that is widely used as a removable denture plate, even since 1946, as many as $98 \%$ of denture plates are PMMA. ${ }^{2}$ Heat-cured acrylic resins are used in almost all denture plates while self-adhesive acrylic resins-cured is more widely used as a denture plate repair material. ${ }^{3}$ PMMA fulfils ideal denture plate requirements, including good dimensional accuracy and stability, biocompatible, aesthetically good, easily manipulated, and relatively inexpensive costs. ${ }^{4}$ PMMA also has deficiencies, such as easily broken, the presence of residual monomers, easily porous, absorbs water and less resistant to abrasion. ${ }^{5}$ The presence of residual monomers namely methylmethacrylate (MMA) can cause hypersensitivity of oral mucosal tissue, burning sensation, and cells cytotoxic. ${ }^{6}$ Residual monomers also have a plasticizing effect which can weaken the mechanical strength of PMMA. ${ }^{3}$

Surface modification of PMMA with silica coating has been widely studied can develop biocompatibility properties of denture plates because it can reduce the attachment of pathogenic microorganisms, and can improve the surface properties of PMMA. ${ }^{7}$ Silica coatings are widely studied because the use of coating material does not change the nature of PMMA as a whole but can modify its surface properties. ${ }^{9}$ Silica coating with a concentration of $2 \%$ can reduce the attachment of $C$. albicans to PMMA denture plates. ${ }^{7}$

Silica with $\mathrm{SiO}_{2}$ molecular formula consists of one silicon atom ( $\mathrm{Si}$ ) and is surrounded by four oxygen atoms $\left(\mathrm{O}_{2}\right)$. Silica which fulfils for coating materials is nano-silica particles, because it has advantages such as small particle size, large surface area, strong interaction with organic polymers, non-toxic, antifungal and antibacterial properties, and can provide resistance to medical materials teeth against the pressure or force that causes cracking. ${ }^{10}$

$\mathrm{SiO}_{2}$ can react with PMMA by binding to an alkoxy group on silane (3-methacryloxypropyl trimethoxysilane) to form a hydroxyl bond (Si$\mathrm{OH})$, afterwards, through the heating process with an oven, it will showed a biocompatibility in a siloxane layer consisting of -Si-O-Si-O-Si- bonds at PMMA. ${ }^{7,8,11}$ Nano silica particles are able to increase the strength and density of the polymer chain of a material. ${ }^{12}$ The coating process provides additional heating on acrylic resin denture plates, thereby increasing the degree of monomer conversion more completely. ${ }^{13}$ The purpose of this study was to analyse the silica coating application on heat-cured acrylic resin plates towards the surface hardness and the amount of residual monomers.

\section{METHODS}

This study was an experimental laboratory with 40 research subjects in the form of a $13 \times 13 \times$ $2 \mathrm{~mm}$ heat-cured acrylic resin plate, divided into two groups $(n=20)$, control group and silica coating group. The tools used in this study included: digital scale, beaker glass, magnetic stirrer, oven (Panasonic ${ }^{\circledR}$, Japan - $220 \mathrm{~V} / 50$ $\mathrm{Hz}$ ), Vickers Hardness Tester for surface hardness testing, distillation flask with water cooling for the leaching process of residual monomers, and Gas Chromatograph (GC-Shimadzu®, Japan) for calculation of residual monomer content. Materials used in this study included: nanosilica particles (Sigma ${ }^{\circledR}$, Aldrich), heat-cured acrylic resin (QC-20, Dentsply $\left.{ }^{\circledR}\right)$, ethanol as a solvent for coating materials, silane (Ultradent ${ }^{\circledR}$ Silane, Fondaco), ethyl acetate for the leaching of residual monomers, and methyl methacrylate solution as standard monomers for calculating residual monomer levels.

The sample used in this study were 40 acrylic resin plates measured $13 \times 13 \times 2 \mathrm{~mm}$. The acrylic resin plate was fabricated according to the standard procedure of polymerisation of heat-cured QC-20 (Dentsply $®$ ) acrylic resin using conventional water bath techniques. Fabrication of acrylic resin plate samples was carried out at the Dental Engineering Laboratory of Faculty of Dentistry Gadjah Mada University. Samples were divided into two groups $(n=20)$, namely the control group and the acrylic resin plate group applied with a silica coating.

Fabrication of silica coating $2 \%$ was performed by dissolving 2 grams of nano-silica particles into $100 \mathrm{ml}$ of ethanol using a magnetic stirrer, carried out at the Integrated Research Laboratory of Faculty of Dentistry Gadjah Mada University. ${ }^{7,8}$ Acrylic resin plates included in the 
silica coating group were smeared using the silane material 3-methacryloxypropyl trimethoxysilanes (Ultradent ${ }^{\circledR}$ Silane, Fondaco) then dried, then the acrylic resin plate was applied with a silica coating solution using the dip-coating method and heated in an oven (Panasonic ${ }^{\circledR}$, Japan - $220 \mathrm{~V} / 50$
$\mathrm{Hz}$ ) at a temperature of $70^{\circ} \mathrm{C}$ for 10 minutes. ${ }^{11,14}$ Specimens in the control group and silica coating group were immersed in distilled water for 48 hours at the room temperature of $37^{\circ} \mathrm{C}$ before surface hardness and residual monomer tests were carried out.

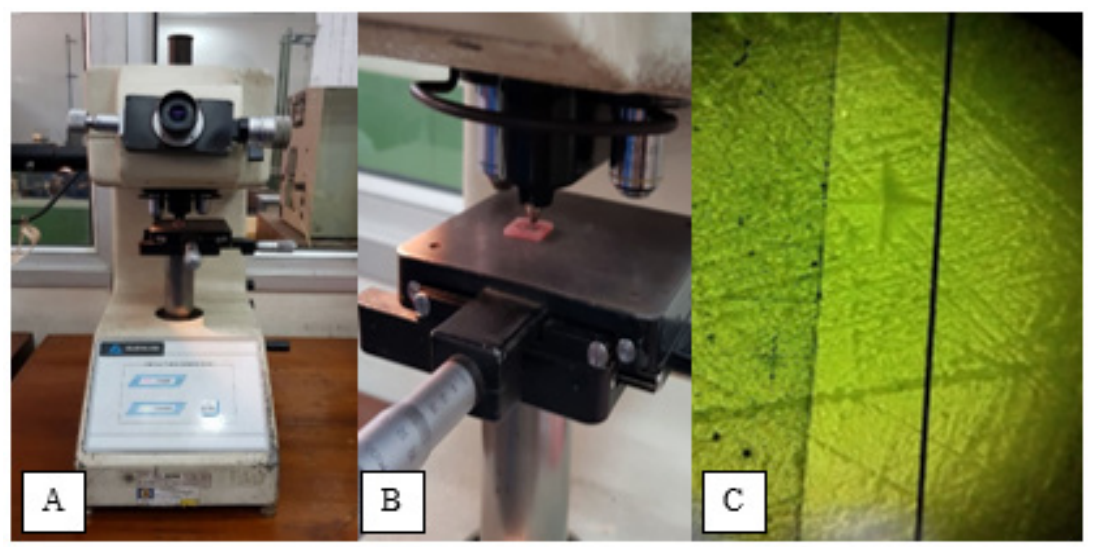

Figure 1. Surface hardness test: A. Vickers Hardness Tester; B. Indentation of specimens; C. Results of diamond-shaped lesions

Surface hardness test using Vickers Hardness Tester with a load of 100 grams for 15 seconds was carried out at the Mechanical Engineering Laboratory of Material Science, Faculty of Engineering Gadjah Mada University. The rhombusshaped test results have been measured the length of the two diagonals and entered into the Vickers Testing Formula.

Residual monomer testing was performed using gas chromatography (GC) tool to calculate the levels of methyl methacrylate in a sample. The chromatography process was the result of repeated sorption and desorption processes during the movement of sample components by the carrier gas. The working principle of GC was that the sample solution was injected into the carrier gas stream. Usually, helium or nitrogen, which will move the sample to a separation tube called a column. In this column the various components were separated, and after exiting will be measured by the detector. After the detector recognised the sample components to be tested, the data will be described by the computer in the form of graphs and numbers as chromatograms. ${ }^{16,17}$

Acrylic resin plates were cut into small pieces using cutting pliers and immersed in distillation flasks with $25 \mathrm{ml}$ ethyl acetate liquid for the leaching process of the remaining acrylic resin plates. Distillation flask was heated with

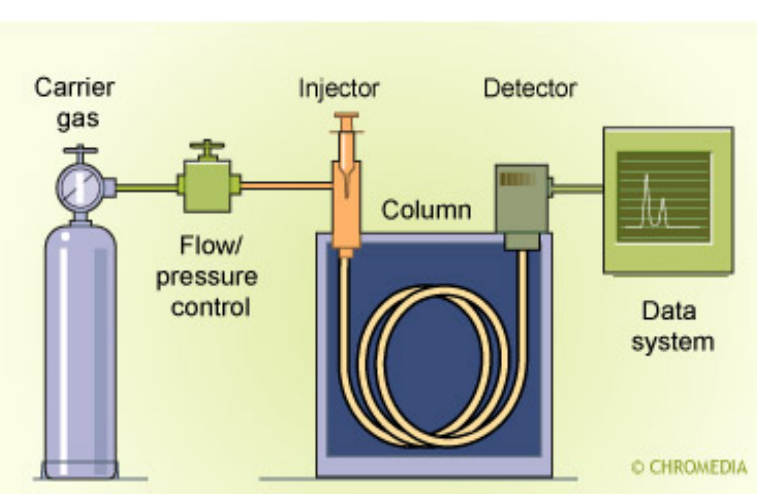

Figure 2. Gas Chromatography (GC) working schematics. ${ }^{15}$

an oil heater at the temperature of $130^{\circ} \mathrm{C}$ then the temperature was lowered by cooling water for 1 hour. The solution obtained was then analysed using a GC tool with the Flame Ionization Detector (FID) technique in the Organic Chemistry Laboratory of the Faculty of Mathematics and Natural Sciences Gadjah Mada University. ${ }^{17}$ The condition of the GC tool was set with a column temperature of $40^{\circ} \mathrm{C}-300^{\circ} \mathrm{C}$ and a column length of $30 \mathrm{~m}$. The temperature at the time of injection was $320^{\circ} \mathrm{C}$ with an injection volume of $0.2 \mu \mathrm{L}$ and the total time for each injection was 60 minutes.

The carrier gas used to analyse the MMA levels in GC was helium, gas which carried MMA analyte and ethyl acetate solvent moved in the column and underwent a separation process. The detector will describe several analytes peaks 
according to the length of time of the analyte in the stationary phase so that the retention time and area of retention were obtained as parameters in calculating the concentration of the sample being sought. MMA standard calculations were carried out to produce a linear equation that produces the values of $a$ and $b$ with a linear equation such as follows: $y=b x+a .{ }^{18}$ After obtaining the value of $y$ from the MMA area on the chromatogram, a percentage weight of MMA was calculated in the acrylic resin plate sample in grams. Data obtained from surface hardness test and residual monomer test were each analysed statistically to determine whether there were significant differences between the control group and the silica coating group by using the Independent t-test.
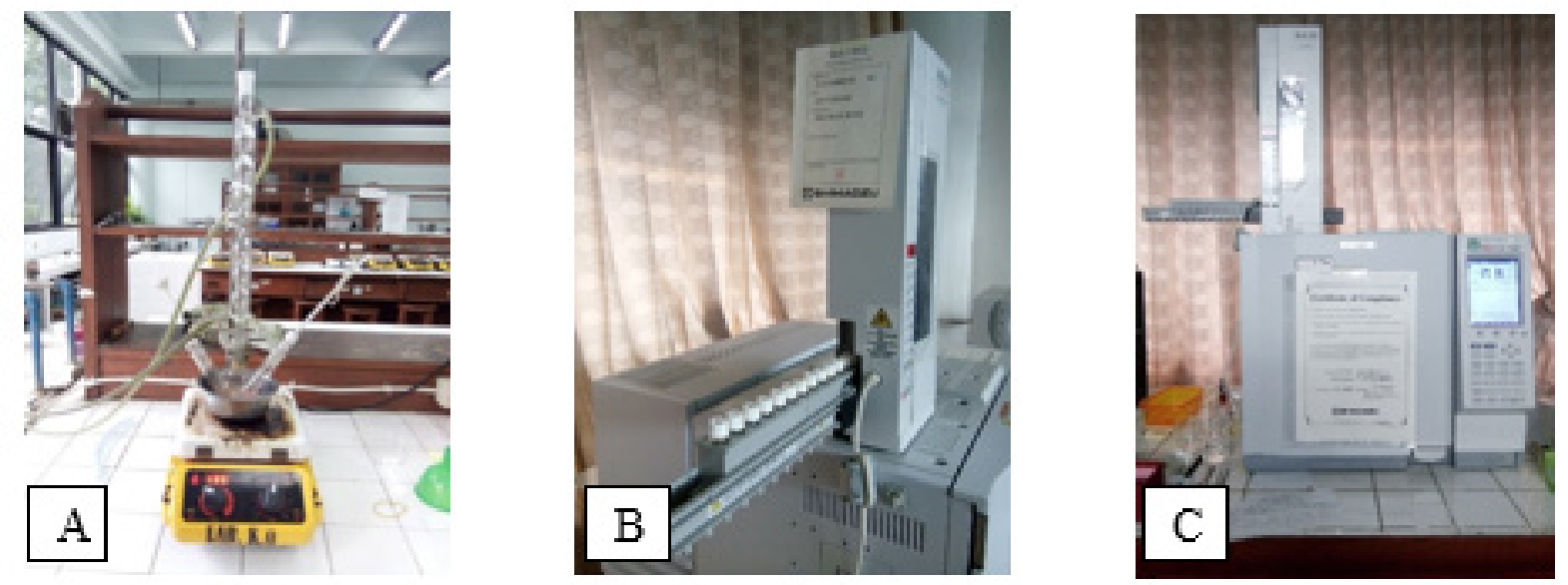

Figure 3. Residual monomers test: A. Leaching process of residual monomers in distillation flasks; B. Injection process in GC tools; C. Gas Chromatography device (Shimadzu®, Japan). ${ }^{15}$

\section{RESULTS}

The results showed the mean value of surface hardness in the silica coating group was higher than in the control group, whereas the average number of monomers remaining acrylic resin plate samples in the silica coating group was lower than the control group. The average table of surface hardness values for each group can be seen in Table 1, while the average table of the remaining monomers for each group can be seen in Table 2.

Table 1. Mean and standard deviation of surface hardness of heat-cured acrylic resin denture $\left(\mathrm{kg} / \mathrm{mm}^{2}\right)$

\begin{tabular}{cc} 
Group & Mean \pm SD \\
Control & $14.59 \pm 4.28$ \\
Silica coating & $25.53 \pm 4.16$ \\
\hline
\end{tabular}

Table 2. Mean and standard deviation of the amount of residual monomers heat-cured acrylic resin denture (g)

\begin{tabular}{cc} 
Group & Mean \pm SD \\
Control & $0.00429 \pm 0.00024$ \\
Silica coating & $0.00183 \pm 0.00004$ \\
\hline
\end{tabular}

The results of the study were tested using an independent $\mathrm{t}$-test provided that the data were normally distributed, while the data variants in both groups could be homogeneous or non-homogeneous. Data normality test using the Shapiro-Wilk test obtained that all research data were normally distributed $(p>0.05)$. Homogeneity test results using the Levene test showed that the surface hardness value data had a homogeneous variant $(p>0.05)$ while the amount of residual monomer data had a non-homogeneous variant $(p<0.05)$. Homogeneity test results can be seen in Table 3 .

Table 3. Homogeneity test results using the Levene test

\begin{tabular}{ccccc}
\hline \multicolumn{5}{c}{ Levene's test } \\
\hline Variable & $\begin{array}{c}\text { Levene's } \\
\text { statistical } \\
\text { value }\end{array}$ & df1 & df2 & Probability \\
\hline $\begin{array}{c}\text { Surface hardness } \\
\text { Residual } \\
\text { monomer } \\
\text { amount }\end{array}$ & 0.029 & 1 & 30 & 0.865 \\
\hline
\end{tabular}

Independent t-test on the surface hardness data obtained significance results of 0.000 , which indicated that there was a significant difference 
between the surface hardness value of the control group and silica coating group $(p<0.05)$. The results of independent $t$-test can be seen in Table 4 . The independent $t$-test on the number of residual monomer data used the value of the degree of freedom from the Satterthwaite equation, sit Kyun Kim. Specifically for the Independent t-test in non-homogeneous population variants, the significance value was 0.000 , which meant that there was a significant difference between the number of residual monomers in the control group and the silica coating group $(\mathrm{p}<0.05) .{ }^{19}$

Table 4. Independent t-test

\begin{tabular}{ccc}
\hline \multicolumn{3}{c}{ Independent t-test } \\
\hline Variable & Df & Probability \\
\hline Surface hardness & 30 & 0.000 \\
Residual monomer amount & 15.755 & 0.000 \\
\hline
\end{tabular}

\section{DISCUSSION}

The results presented in Table 1 show the surface hardness of acrylic resin denture plates in the silica coating group was higher than in the control group. Table 4 shows the significant differences in the mean surface hardness between the control group and silica coating group $(p<0.05)$. This result was consistent with previous research conducted by Kamonwanon et al. ${ }^{8}$ which proved in the examination using Fourier Transform Infra-Red spectroscopy (FT-IR Spectrometer) that the silica coating will form a strong covalent bond ( $\mathrm{Si}-\mathrm{O}-\mathrm{Si}$ ) with a PMMA polymer. ${ }^{8}$ Silica coating reacts with PMMA by binding to the alkoxy group on the silane ( 3-methacryloxypropyl trimethoxysilanes) forms a hydroxyl bond $(\mathrm{Si}-\mathrm{OH})$, then a siloxane layer is formed which consists of a bond - $\mathrm{Si}-\mathrm{O}-\mathrm{Si}$ - in PMMA. ${ }^{8}$ This condition was also supported by Matinlinna and Vallittu's research ${ }^{20}$ which stated that the 3-methacryloxypropyl content trimethoxysilane in silane was effectively used as a coupling agent to synthesise silica in the coating process. ${ }^{20}$ Research conducted by Jafari et al. ${ }^{21}$ also suggested that the coating was able to prevent microcrack and microporous on acrylic resin denture plates, thereby increasing the surface hardness of acrylic resin denture plates. ${ }^{21}$

The results presented in Table 2 show that the average number of monomers remaining in the silica coating group was lower than the control group. Table 4 shows a significant difference in the mean number of residual monomers between the control group and the silica coating group ( $\mathrm{p}$ $<0.05$ ). This result was consistent with previous studies conducted by Feng et al. ${ }^{13}$ which stated that the heating process of coating on acrylic resin denture plates provided secondary polymerisation to acrylic resin plates and able to reduce the amount of residual monomers effectively. ${ }^{13}$ The degree of polymerisation increases indicated that the number of perfectly polymerised monomers increases so that the number of residual monomers decreases. The present result was consistent with Combe and Grant's statement ${ }^{6}$ that the number of monomers polymerised and joined together to form polymers determines the degree of polymerization. ${ }^{6}$

The increase in the degree of polymerisation caused a decrease in the average number of residual monomers in the silica coating group, as well as in the surface hardness test, the average value of surface hardness increased. The control group which had a higher average remaining number of monomers had a lower mean surface hardness value. This condition was occurred because the degree of polymerisation determines the molecular weight of a polymer, and the molecular weight can affect mechanical strength. This result was consistent with the statement of Powers and Sakaguchi ${ }^{5}$, which stated that the polymerisation of acrylic resin as a denture plate material was intended to turn all monomer into a polymer to produce optimal mechanical strength. ${ }^{5}$ The presence of residual monomers will affect the molecular weight of the polymer. Annusavice ${ }^{3}$ also supported the statements by suggested that the remaining monomer of $0.9 \%$ at an average molecular weight of 22,400 will reduce the weight of the polymer to about 7,300, and affect the polymer's mechanical strength. ${ }^{3}$ These findings were also consistent with Combe and Grant's finding $^{6}$ regarding the material having a high molecular weight will have higher mechanical strength when compared to materials that have a lower molecular weight. ${ }^{6}$ Based on the results of this study, it is necessary to research further regarding the correlation between the amount of residual monomers with the surface hardness 
of PMMA denture plates on the control group and group with silica coating application.

\section{CONCLUSION}

Silica coating increases the surface hardness and decreases the amount of residual monomer of heat-cured acrylic resin.

\section{REFERENCES}

1. Barclay CW, Walmsey AD. Fixed And Removable Prosthodontics. $2^{\text {nd }}$ ed. London: Churchill Livingstone; 2001.

2. Sakaguchi RL, Powers JM. Craig's Restorative Dental Materials. $13^{\text {th }}$ ed. St. Louis: MosbyElsevier; 2013. p. 25-195.

3. Anusavice KJ, Shen C, Rawls HR. Phillip's science of dental materials. $12^{\text {th }}$ ed. St. Louis: Saunders-Elsevier; 2013. Phillips' science of dental materials. pp.165-6, 721-2.

4. Carr A, Brown D. McCracken's Removable Partial Prosthodontocs. $12^{\text {th }}$ ed. St. Louis: Mosby-Elsevier; 2011. pp. 7, 106-7, 346.

5. Powers JM, Sakaguchi RL. Craig's Restorative Dental Materials (Dental Materials: Properties \& Manipulation (Craig)). 12 th ed. St. Louis: Mosby Elsevier; 2006; p.524-44.

6. Combe EC. Notes of Dental Materials (Dental S.). $6^{\text {th }}$ ed. London: Churchill Livingstone; 1992; pp. 26-8, 79-120, 157-61, 224, 262-69.

7. Azuma A, Akiba N, Minakuchi S. Hydrophilic surface modification of acrylic denture plate material by silica coating and its influence on Candida albicans adherence, J Med Dent Sci. 2012; 59(1): 1-7.

8. Kamonwanon $\mathrm{P}, \quad$ Yodmongkol $\mathrm{S}$, Chantarachindawong R, Thaweboon $\mathrm{S}$, Thaweboon B, Srikhirin T. Wear resistance of a modified polymethyl methacrylate artificial tooth compared to five commercially available artificial tooth materials. J Prosthet Dent. 2015; 114(2): 286-92. DOI: 10.1016/j. prosdent.2015.01.013

9. Yoshizaki T, Akiba $\mathrm{N}$, Inokoshi $M$, Shimada M, Minakuchi S. Hydrophilic nano-silica coating agents with platinum and diamond nanoparticles for denture plate materials. Dent Mater J. 2017; 36(3): 333-9. DOI: 10.4012/dmj.2016-243
10. Zayed SM, Alshimy AM, Fahmy AE. Effect of Surface Treated Silicon Dioxide Nanoparticles on Some Mechanical Properties of Maxillofacial Silicone Elastomer. Int J Biomater. 2014; 2014: 1-7. DOI: $10.1155 / 2014 / 750398$

11. Gul EB, Atala MH, Eser B, Polat NT, Asilturk M, Gultek A. Effects of coating with different ceromers on the impact strength, transverse strength and elastic modulus of polymethylmethacrylate. Dent Mater J. 2015; 34(3): 379-87. DOI: 10.4012/dmj.2014-203

12. Yodmongkol $S$, Chantarachindawong $R$, Thaweboon S, Thaweboon B, Amornsakchai $\mathrm{T}$, Srikhirin T. The effects of silane-SiO2 nanocomposite films on Candida albicans adhesion and the surface and physical properties of acrylic resin denture plate material. J Prosthet Dent. 2014; 112(6): 15308. DOI: $10.1016 / j$.prosdent.2014.06.019

13. Feng $D$, Gong $H$, Zhang J, Guo X, Yan M, Zhu S. Effects of antibacterial coating on monomer exudation and the mechanical properties of denture plate resins. J Prosthet Dent. 2017; 117(1): 171-7. DOI: 10.1016/j. prosdent.2016.05.009

14. Amano $D$, Ueda $T$, Sugiyama $T$, Takemoto $S$, Oda Y, Sakurai K. Improved brushing durability of titanium dioxide coating on polymethylmethacrylate substrate by prior treatment with acryloxypropyl trimethoxysilane $\neg$ plated agent for denture application. Dent Mater J. 2010; 29(1): 97 103. DOI: $10.4012 / \mathrm{dmj} .2009-073$

15. Suhono RS. Pengaruh Silica Coating pada Plat Gigi Tiruan Resin Akrilik Heat-cured terhadap Kekerasan Permukaan dan Jumlah Monomer Sisa [thesis]. Yogyakarta: Gadjah Mada University. 2018. p.73.

16. Niessen WMA. Current Practice of Gas Chromatography-Mass Spectrometry. New York: Marcel Dekker; 2001. pp. 2, 28.

17. Dipoyono HM. Silanisasi Monomer Sebagai Upaya Peningkatan Kekuatan Polimer Resin Akrilat [dissertation]. Surabaya: Airlangga University. 1991. p. 61-2.

18. Linan LZ, Bonon A, Lima NMN, Filho RM, Manenti F. Quality Control of Poly(Methyl Methacrylate) to Medical Purpose by Multiple Headspace Extraction. Chem Eng Trans. 2013; 32: 1699-1704. DOI: 10.3303/CET1332284 
19. Kim TK. T-test as a parametric statistic. Korean J Anesthesiol. 2015; 68(6): 540-6. DOI: 10.4097/kjae.2015.68.6.540

20. Matinlinna JP, Vallittu PK. Bonding of Resin Composites to Etchable Ceramic SurfaceAn Insight Review of the Chemical Aspect on Surface Conditioning. J Oral Rehabil.
2007; 34(8): 622-30. DOI: $10.1111 / \mathrm{j} .1365-$ 2842.2005.01569.x

21. Jafari AA, Lotfi-Kamran MH, Ghafoorzadeh $M$, Shaddel SM. Evaluation of Surface Characteristics of Denture Plate Using OrganicInorganic Hybrid Coating:An SEM Study. J Dent Biomater. 2017; 4(2): 403-8. 